\title{
Clinical Radiology for Pediatricians: Binit Sureka, Aliza Mittal (eds)
}

\author{
Published by Peepee Publishers \& Distributors; First Edition: 2015; ISBN: 978-81-8445- \\ 177-1; Pages: 200
}

\author{
Kushaljit Singh Sodhi ${ }^{1}$
}

Received: 23 July 2015 / Accepted: 23 July 2015 /Published online: 20 August 2015

(C) Dr. K C Chaudhuri Foundation 2015

Radiology is considered an integral part of clinical examination in the present era and plays even more significant role in the diagnostic algorithm in the pediatric population. Knowledge of imaging features of many distinct disease spectra can help in early diagnosis and prompt management of these children.

There are not many focused Indian books in the field of pediatric radiology that cater to the needs of general practitioners and pediatric students. One of the new additions is the "Clinical Radiology for Pediatricians" by Dr. Binit Sureka and Dr. Aliza Mittal. Dr. Binit Sureka is a radiologist while Dr. Aliza Mittal is a pediatrician. The combined contribution of radiologist and pediatrician makes this book more practical and meaningful, especially for the pediatrics trainee.

This short hand book of 200 pages, has been divided into nine chapters which includes a 'brainstorming' chapter at the end of the book, which is meant for a quick revision of the commonly encountered cases and can be read as 'quiz' by the graduates or post graduates. This book starts with a brief 'Introduction', which covers technical aspects, effective radiation doses and guidelines. Subsequently, it has been divided into chapters based on different systems (chest, cardiac, musculoskeletal, gastrointestinal, central nervous and genitourinary systems).

Tables, images and other illustrations have been blended well with neatly arranged text in this book. All disease entities have a brief relevant text at the start followed by a typical radiological image of the entity, to make it easier for the residents and clinicians to comprehend. Many tables of differential diagnosis and radiological appearances have been listed which would be useful in daily practice.

Altogether, the book is easy to read, well organized and is a compact book that illustrates radiology of common entities in day-to-day clinical pediatric practice. It shall be helpful to both students pursuing careers in pediatrics, radiology and to practicing pediatricians.

Kushaljit Singh Sodhi

sodhiks@gmail.com

1 Department of Radiodiagnosis, Postgraduate Institute of Medical Education and Research, Chandigarh 160012, India 